\title{
REFERENTIAL GESTURES ARE NOT UBIQUITOUS IN WILD CHIMPANZEE COMMUNITIES
}

\author{
KATIE E. SLOCOMBE ${ }^{* 1}$, NICOLE LAHIFF ${ }^{1}$, CLAUDIA WILKE $^{1}$ and CAT \\ HOBAITER $^{2}$ \\ *Corresponding Author: katie.slocombe@york.ac.uk \\ ${ }^{1}$ Department of Psychology, University of York, York, UK \\ ${ }^{2}$ School of Psychology and Neuroscience, University of St Andrews, UK
}

Referential gestures such as pointing are ubiquitous in human societies and the production and comprehension of referential gestures requires many of the cognitive capacities also crucial for language, including reading intentions and establishing common ground (Tomasello 2008). Given the importance of referential gesturing in human communication, there has been significant debate over the evolutionary origins of this behavior. Although captive and enculturated chimpanzees spontaneously learn to point referentially for human caregivers (Leavens et al., 2004), habitual use of referential gestures was thought to be absent in wild chimpanzees, until Pika and Mitani (2006) reported the use of 'directed scratches' during grooming bouts amongst male dyads in the Ngogo community of chimpanzees. In this community, after the recipient of grooming scratched his own body, in $64 \%$ of cases, the groomer then groomed the scratched location. Pika and Mitani concluded that wild chimpanzees use gestures to specify where they want to be groomed and that these scratch gestures were both referential and iconic. In an attempt to replicate and extend these findings we recorded dyadic grooming bouts in the Kanyawara and Sonso communities of chimpanzees, located approximately 10 and 200km from the Ngogo community in Uganda.

Grooming interactions were filmed and we coded all instances of 'big loud scratches' and 'present body part' gestures (where a body part is moved towards the groomer possibly to request grooming in that broad body area), of which only the former has been argued to be referential. We identified all scratches given by recipients of grooming and coded whether the groomer groomed within $5 \mathrm{~cm}$ of the scratched location in the 10 seconds after the scratch ended. In cases where the groomer did not begin grooming in the scratched location, we then examined 
whether the signaler repeated the scratch gesture in the same location (persistence) or presented the same body part to the groomer (elaboration) in the 30 seconds after the first scratch ended. Such persistence and elaboration behaviours would have indicated that the signaler's goal was to request grooming in a specific location.

We found little evidence of chimpanzees in Sonso and Kanyawara communities using 'big loud scratch' gestures to request grooming in a specific location. Very few scratches elicited grooming in the scratched location, and when the groomer failed to groom the scratched location, very few instances of persistence or elaboration to reach the goal were shown. This indicates that in these two communities of wild chimpanzees the signaler's goal is not to elicit grooming in a specific location. In contrast, we found 'present groom' gestures were highly successful in eliciting grooming on the presented body part and that big loud scratches were frequently used to initiate grooming bouts.

These findings show that the habitual use of referential gestures with conspecifics is not a universal aspect of chimpanzee communication and it highlights the importance of replicating important findings in multiple populations. Our findings raise the intriguing possibility that the referential use of the big loud scratch gesture is culturally specific to the Ngogo community, and thus more detailed analysis of this behavior and examination of the signaler's goals and circumstances that have given rise to this form of communication are required in this community. For now, it seems that when not faced with the 'referential problem space' that captivity brings (Leavens et al., 2005), not all wild chimpanzees habitually produce referential gestures and referential gesturing is not a ubiquitous feature of chimpanzee communication.

\section{References}

Leavens, D. A., Hopkins, W. D., \& Thomas, R. K. (2004). Referential communication by chimpanzees (Pan troglodytes). Journal of Comparative Psychology, 118(1), 48.

Leavens, D. A., Hopkins, W. D., \& Bard, K. A. (2005). Understanding the point of chimpanzee pointing: epigenesis and ecological validity. Current Directions in Psychological Science, 14(4), 185-189.

Pika, S., \& Mitani, J. (2006). Referential gestural communication in wild chimpanzees (Pan troglodytes). Current Biology, 16(6), R191-R192.

Tomasello, M. (2008). Origins of human communication. Cambridge, MA: MIT press. 